\title{
GECE VE GÜNDÜZ YER YÜZEY SICAKLIĞI GÖRÜNTÜLERİ İLE YÜZEY ISI ADASI ANALIZí
}

\author{
Aliihsan ŞEKERTEKİN ${ }^{1}$, Sevim Yasemin ÇİÇEKLI², Niyazi ARSLAN
}

\begin{abstract}
${ }^{1}$ Arş. Gör. Dr., Çukurova Üniversitesi, Ceyhan Mühendislik Fakültesi, Harita Mühendisliği Bölümü, 01950, Ceyhan/ADANA, asekertekin@cu.edu.tr ${ }^{2}$ Arş. Gör., Cukurova Üniversitesi, Ceyhan Mühendislik Fakültesi, Harita Mühendisliği Bölümü, 01950, Ceyhan/ADANA, yoturanc@cu.edu.tr ${ }^{3}$ Doç. Dr., Çukurova Üniversitesi, Ceyhan Mühendislik Fakültesi, Harita Mühendisliği Bölümü, 01950, Ceyhan/ADANA, narslan@cu.edu.tr
\end{abstract}

\section{ÖZET}

Günümüzde yerel iklim değişiklikleri etkisinin giderek artış göstermesi nedeniyle iklim parametrelerinden biri olan yüzey sicaklıklarının izlenmesi önemli olup termal uzaktan algılama yöntemleriyle izlenebilmektedir. Uzaktan algllama teknikleri ile elde edilen termal görüntülerin belli algoritmalar yardımıyla işlenmesiyle Yer Yüzey Sıcaklı̆̆ (YYS) görüntüleri elde edilebilmektedir. Bu çalışmanın amacı, Terra uydusu üzerinde yer alan ASTER (Advanced Spaceborne Thermal Emission and Reflection Radiometer) algılayıcısına ait veriler kullanılarak gece ve gündüz YYS görüntülerinin çıkarılması ve YYS verileri ile Yüzey Isı Adası (YIA) analizlerinin gerçekleştirilmesidir. ASTER algılayıcısına ait 03/07/2013 tarihinde alınan görüntülerden gece görüntüsü Türkiye saati ile 22.36'da gündüz görüntüsü ise 11.33 'te alınmıştır. Çalı̧̧mada, ASTER verileri mono-window algoritması ile işlenerek YYS görüntüleri üretilmiştir. Çalışma alanı olarak Adana ilinin merkez ilçeleri dışında en fazla nüfusa sahip olan Ceyhan ilçesi seçilmiştir. Çalışma sonucunda üretilen YYS görüntüleri üzerinde YIA analizi gerçekleştirmek amacıyla farklı Arazi Kullanımı Arazi Örtüsü (AKAÖ) türlerinin gece ve gündüz sahip olduğu YYS değerleri analiz edilmiştir. YYS görüntüleri MODIS YYS ürünleri ile çapraz doğrulama yöntemi ile doğruluk analizine tabi tutulmuştur. Yapılan analizler ile gündüz en yüksek YYS değerinin nadasa birakılan toprakta elde edildiği gözlemlenirken gece ise kentsel alanlardaki YYS değerinin en yüksek olduğu belirlenmiştir. Çalışa sonucunda, ASTER'in gece ve gündüz verileri sağlaması ile YIA analizinin etkili bir şekilde yapılabildiği gözlemlenmiştir.

Anahtar Sözcükler: yer yüzey sıcaklığı, yüzey 1sı adası, kentsel 1sı adası, ASTER, Ceyhan

\section{ABSTRACT \\ SURFACE HEAT ISLAND ANALYSIS USING DAY-TIME AND NIGHT-TIME LAND SURFACE TEMPERATURE IMAGES}

As the effect of local climate change has been increasing nowadays, monitoring of surface temperatures, one of the climate parameters, is important and can be monitored by thermal remote sensing methods. Land Surface temperature (LST) images can be obtained by processing the thermal images obtained by remote sensing techniques with the aid of certain algorithms. The purpose of this study is to extract night-time and day-time LST images using the data of the ASTER sensor located on the Terra satellite and to perform Surface Heat Island (YIA) analyzes on the basis of LST. Day-time and night-time images of ASTER sensor were acquired on 03.07.2013 with acquisition hour 11:33 and 22:36 respectively. In the study, ASTER data was processed by mono-window algorithm, and thus LST images were produced. Ceyhan, having largest population except for central districts of Adana province, was selected as the study area. As a result of the study, day-time and night-time LST values of different land use land cover types (LULC) were analyzed in order to perform SHI analysis. LST images were subjected to accuracy analysis by cross validation method with MODIS LST products. It was observed that the highest LST value in the daytime was obtained from the fallow land, whereas in the night-time, YYS value in the urban areas was found to be the highest. As a result of the study, it was observed that ASTER could perform the SHI analysis efficiently with the day and night-time data.

Keywords: land surface temperature, surface heat island, urban heat island, ASTER, Ceyhan

\section{GíRiş}

Termal uzaktan algılama, elektromanyetik spektrumun kızılötesi bölgesini esas alır ve cisimden yayılan termal enerjiyi ölçer. Cisimden doğal olarak yayılan enerjiyi algıladığı için bir tür pasif uzaktan algılama sistemidir. Yer Yüzey Sıcaklı̆ı̆ (YYS), termal uzaktan algılamanın önemli başlıklarından biri olmakla birlikte son yıllarda yerel ve küresel iklim değişikliği çalışmalarında sıkça kullanılan bir kavramdır. Kentsel Isı Adası (KIA) etkisi, kentsel alanlardaki sıcaklıkların çevresindeki kırsal alanlara nazaran daha yüksek seviyelerde olmasıdır. Yüzey Isı Adası (YIA), uzaktan algılama ile elde edilen verilerden üretilen bir KIA türüdür ve YYS görüntüleri YIA kavramını temsil etmektedir. Klok vd. (2012) tarafından yapılan çalışmada, Rotterdam (Hollanda) şehrinin YIA'nı konumsal olarak belirlemek için Landsat verileri kullanılmış ve gündüz YIA yoğunluğunun $10^{\circ} \mathrm{C}$ 'ye kadar yükseldiği görülmüştür. Peng vd. (2012) yaptıkları çalışmada, gündüz ve gece zamanı için sezonsal YIA yoğunluğunu MODIS YYS verileri ile analiz etmişlerdir. Çalışma sonucunda bitki örtüsünün YIA etkisini azaltmak için önemli bir faktör olduğu vurgulanmıştır. Martin vd. (2015) yaptıkları çalışmada, Landsat verilerinden elde edilen YYS verileri bir zaman serisi analizi gerçekleştirmiş ve YIA analizinden kırsal alanların karşılaştırmasını çıkararak yeni bir YIA 
tanımı ortaya koymuştur. Şekertekin vd. (2016) yaptıkları çalışmada, Landsat verileri ile endüstriyel alanlardaki YIA etkisini incelemişlerdir. Çalışmanın sonucunda endüstriyel alanlardaki konumsal ve zamansal analizler, bu alanların çevrelerine nazaran daha yüksek YYS değerlerine sahip olduğunu göstermiştir.

Farklı veri kaynaklarına göre YYS elde etme yöntemleri geliştirilmiştir. Bu yöntemler arasında en çok kullanılan algoritmalar; split-window yöntemi (Sobrino vd., 1996), sıcaklık/yayınırlık ayırma (temperature/emissivity separation) yöntemi (Gillespie vd., 1998), mono-window algoritması (Qin vd., 2001) ve single channel yöntemidir (Jimenez-Munoz ve Sobrino, 2003). Bu çalışmada, orijinalinde Landsat verisi için üretilen mono-window algoritması ASTER (Advanced Spaceborne Thermal Emission and Reflection Radiometer) termal verisine uyarlanarak kullanılmıştır. Çalışmanın amacı, Terra uydusu üzerinde bulunan ASTER algılayıcısına ait veriler kullanılarak mono-window algoritması ile gece ve gündüz YYS görüntülerinin çıkarılması ve YYS sonuçları ışı̆̆ında YIA etkisinin analiz edilmesidir.

\section{2. ÇALIŞMA ALANI}

Çalışma alanı olarak fakültemizin içinde bulunduğu Adana ilinin Ceyhan ilçesi ele alınmıştır. Merkez ilçelerin dışında Adana'nın en büyük ilçesi olan Ceyhan, Toros dağlarından denize doğru uzanan Yukarı Çukurova bölümünün ortasında, Ceyhan Nehri'nin doğu sahilinde kurulmuştur (Şekil 1). Güneyde Yumurtalık, kuzeyde Kozan, kuzeybatısında İmamoğlu, kuzeydoğusunda Kadirli, doğuda Osmaniye, Hatay ilinin Erzin ilçesi ve batıda Yüreğir ile komşudur. Bölgede tarımcılık başlıca geçim kaynağıdır ve tarım alanları ile kentsel ve kırsal alanlar birbiri ile iç içedir.

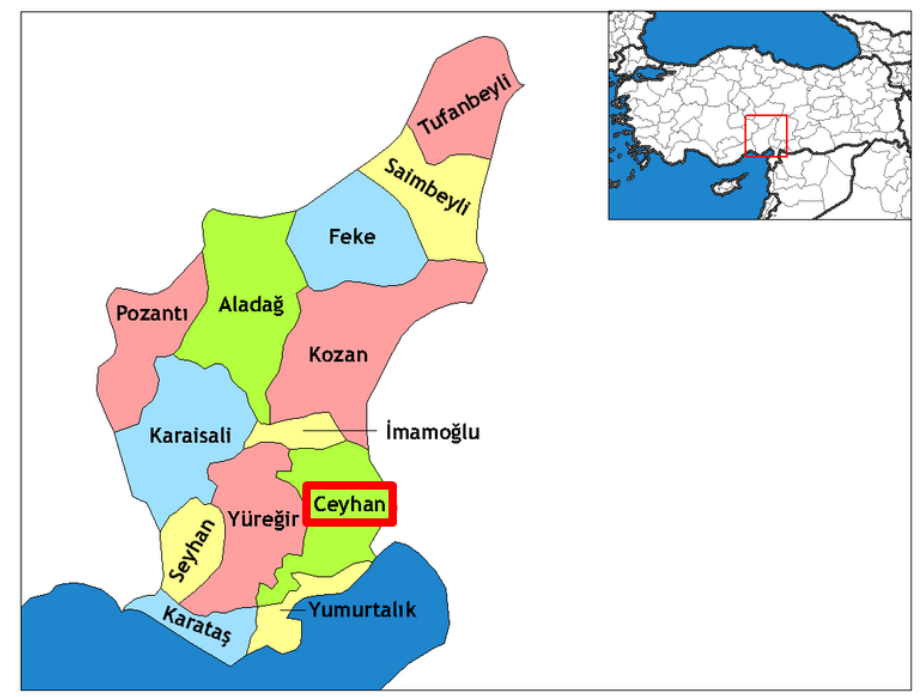

Şekil 1. Çalışma alanının genel görünümü.

\section{MATERYAL VE YÖNTEM}

Çalışmada, Adana ilinin merkez ilçeleri dışındaki en fazla nüfusa sahip ilçesi olan Ceyhan'a ait ASTER görüntüleri Amerikan Jeoloji Birliğinin (USGS) sitesinden ücretsiz olarak temin edilmiştir. ASTER görüntüleri gece ve gündüz zamanları için aynı tarih olan 03/07/2013 tarihinde alınmış olmakla birlikte gündüz görüntüsü saat 11.33 'te, gece görüntüsü ise 22.36 ' da sensör tarafindan kaydedilmiştir.

Qin vd. (2001) tarafindan yapılan çalışmada, Landsat TM görüntülerinden mono-window algoritması ile YYS görüntüleri elde edilmiştir. ASTER algılayıcısı beş adet termal banda sahip olmakla birlikte dalga boyu Landsat TM'den elde edilen termal banda en yakın olan 14. Banttır ve çalışmada bu band kullanılmıştır. Mono-window algoritması için üç ana parametre gerekmektedir. Bunlar; yayınırlık, atmosferik geçirgenlik ve ortalama atmosferik sıcaklıktır. Bu verilerin algoritma denklemleri yardımıyla elde edilebilmesi için meteoroloji genel müdürlüğünden bu görüntülere ait tarihlerdeki sıcaklık ve nem verileri de alınmıştır. Mono-window algoritmasının temel adımlar ve detayları aşağıdaki gibi sıralanabilir. Adımların uygulandığı bantlar parantez içinde gösterilmiştir.

Parlaklık değerlerinin spektral radyans değerlerine dönüştürülmesi (Red: R, Near Infrared: NIR, Termal: TIR)

Bu dönüşüm için (1) nolu denklem kullanılmaktadır. 
$\mathrm{L}_{\lambda \mathrm{i}}=\left(\mathrm{DN}_{\mathrm{i}}-1\right) \times \mathrm{UCC}_{\mathrm{i}}$

$\mathrm{L}_{\lambda \mathrm{i}}$ ilgili banda ait spektral radyans değerini $\mathrm{W} /\left(\mathrm{m}^{2 *} \mathrm{sr}^{*} \mu \mathrm{m}\right), \mathrm{DN}_{\mathrm{i}}$ ilgili bandın piksel değerlerini, $\mathrm{UCC}_{\mathrm{i}}$ ASTER kullanım kılavuzundan alınan Birim Dönüşüm Katsayısını temsil etmektedir.

\section{$>$ Spektral radyans değerlerinin yansıtım değerlerine dönüştürülmesi (R, NIR)}

Bu dönüşüm R ve NIR bandlara (2) no’lu denklem kullanılarak uygulanmaktadır.

$\rho_{\mathrm{p}}=\frac{\pi \cdot \mathrm{L}_{\lambda \mathrm{i}} \cdot \mathrm{d}^{2}}{\mathrm{ESUN}_{\lambda} \cdot \cos \theta_{\mathrm{s}}}$

$\rho_{p}$ birimsiz spektral yansıtım değerini, $L_{\lambda i}$ spektral radyans değerini, d astronomik birimdeki Dünya-Güneş mesafesinin, $\operatorname{ESUN}_{\lambda}$ solar irradyans değerini ve $\theta_{\mathrm{s}}$ güneş zenit açısını temsil etmektedir.

\section{Radyans değerlerinin parlaklık sıcaklığı değerlerine dönüş̧ürülmesi (TIR)}

Bu dönüşüm (3) no’lu denklem kullanılarak yalnızca termal banda uygulanmaktadır.

$$
\mathrm{T}=\frac{\mathrm{K}_{2}}{\ln \left(\frac{\mathrm{K}_{1}}{\mathrm{~L}_{\lambda}}+1\right)}
$$

T Kelvin cinsinden parlaklık sıcaklığını, $\mathrm{K}_{1} 1$ nolu kalibrasyon sabitini, $\mathrm{K}_{2} 2$ nolu kalibrasyon sabitini, $\mathrm{L}_{\lambda}$ spektral radyans değerini temsil etmektedir. Band 14 için $\mathrm{K}_{1}: 641.3265\left(\mathrm{Wm}^{-2} \mu \mathrm{m}^{-1}\right), \mathrm{K}_{2}$ : 1271.2217 (K)'dir.

\section{$>$ Yer yüzey yayınırlık ( $\left.\varepsilon_{i}\right)$ hesabı (Normalize Fark Bitki Örtüsü: NDVI tabanlı)}

Yayınırlık hesabı için pratik bir yöntem olan NDVI tabanlı bir yaklaşım ele alınmıştır. Sobrino vd. (2008) ASTER TIR verisinden NDVI tabanlı olarak yayınırlık hesaplanması için pratik denklemler üretmişlerdir. (4) no'lu denklem ile elde edilen NDVI verisi kullanılarak (5) no'lu denklem yardımıyla bitki örtüsü oranı $\left(\mathrm{P}_{\mathrm{v}}\right)$ hesaplanır.

$\mathrm{NDVI}=\frac{\mathrm{NIR}-\mathrm{R}}{\mathrm{NIR}+\mathrm{R}}$

$\mathrm{P}_{\mathrm{V}}=\left[\frac{(\mathrm{NDVI})-(\mathrm{NDVI})_{\min }}{(\mathrm{NDVI})_{\max }-(\mathrm{NDVI})_{\min }}\right]^{2}$

$(\mathrm{NDVI})_{\max }$ ve (NDVI) ${ }_{\min }$ histogram üzerinden elde edilebileceği gibi küresel durumlarda sirasıyla 0.5 ve 0.2 olarak kabul edilmektedir. (Sobrino vd., 2008). ASTER'in 14 no'lu TIR bandı esas alındığında (6) no'lu denklem ile yayınırlık hesabı yapılabilmektedir (Sobrino vd., 2008).

$\varepsilon_{14}=0.970+0.020 \mathrm{P}_{\mathrm{v}}$

\section{$>$ Atmosferik geçirgenlik hesabı $\left(\tau_{\mathrm{i}}\right)$}

Çalışma alanına ait atmosferik geçirgenlik hesabı su buharı içeriği $\left(\mathrm{w}_{\mathrm{i}}\right)$ kullanılarak Çizelge 1'deki denklemler yardımıyla hesaplanabilir (Wang vd., 2015). Su buharı içeriği, meteoroloji istasyonlarından elde edilebilirliğinin yanı sıra hava sıcaklığı ve nispi nem verileri ile de hesaplanabilmektedir (Sekertekin vd., 2016).

Çizelge 1. Çalışma alanı için atmosferik geçirgenlik hesabı.

\begin{tabular}{|c|c|c|c|}
\hline \multirow{2}{*}{ Atmosfer } & $\begin{array}{c}\text { Su Buharı } \\
(\mathbf{w i})\left(\mathbf{g} / \mathbf{c m}^{\mathbf{2}}\right)\end{array}$ & $\begin{array}{c}\text { Geçirgenlik Tahmin } \\
\text { Denklemi }\left(\boldsymbol{\tau}_{\mathbf{i}}\right)\end{array}$ & $\mathbf{R}^{\mathbf{2}}$ \\
\hline \multirow{3}{*}{ Orta-meridyen Yaz } & $0.2-1.6$ & $0.9184-0.0725 \times \mathrm{w}_{\mathrm{i}}$ & 0.983 \\
\cline { 2 - 4 } & $1.6-4.4$ & $1.0163-0.1330 \times \mathrm{w}_{\mathrm{i}}$ & 0.999 \\
\cline { 2 - 4 } & $4.4-5.4$ & $0.7029-0.0620 \times \mathrm{w}_{\mathrm{i}}$ & 0.966 \\
\hline
\end{tabular}




\section{$>$ Ortalama atmosferik sicaklık $\left(T_{a}\right)$ hesabı}

Qin vd. (2001) yakın yüzey sıcaklığı $\left(\mathrm{T}_{\mathrm{o}}\right)$ değerleri ile farklı bölgelerdeki ortalama atmosferik sıcaklığı tahmin edebilmek amacı ile doğrusal dönüşüm denklemleri üretmişlerdir (Çizelge 2).

Çizelge 2. Estimation of mean atmospheric temperature.

\begin{tabular}{|l|c|}
\hline \multicolumn{1}{|c|}{ Bölge } & Ortalama atmosferik sıcaklık $\left(\mathbf{T}_{\mathbf{a}}\right)$ Kelvin \\
\hline USA 1976 & $\mathrm{T}_{\mathrm{a}}=25.9396+0.88045 \times \mathrm{T}_{\mathrm{o}}$ \\
\hline Tropikal & $\mathrm{T}_{\mathrm{a}}=17.9769+0.91715 \times \mathrm{T}_{\mathrm{o}}$ \\
\hline Orta-meridyen Yaz & $\mathrm{T}_{\mathrm{a}}=16.0110+0.92621 \times \mathrm{T}_{\mathrm{o}}$ \\
\hline Orta-meridyen Kiş & $\mathrm{T}_{\mathrm{a}}=19.2704+0.91118 \times \mathrm{T}_{\mathrm{o}}$ \\
\hline
\end{tabular}

\section{$>$ Mono-window algoritması ile YYS hesabı}

Yukarıda detayları verilen tüm parametreler elde edildikten sonra (7) no'lu eşitlikte verilen mono-window denklemi ile YYS değerleri elde edilmektedir.

$$
\mathrm{T}_{\mathrm{s}}=\left\{\mathrm{a} \cdot(1-\mathrm{C}-\mathrm{D})+[\mathrm{b} \cdot(1-\mathrm{C}-\mathrm{D})+\mathrm{C}+\mathrm{D}] \cdot \mathrm{T}_{\mathrm{i}}-\mathrm{D} \cdot \mathrm{T}_{\mathrm{a}}\right\} \div \mathrm{C}
$$

$\mathrm{T}_{\mathrm{s}}$ Kelvin cinsinden YYS değerini, $\mathrm{T}_{\mathrm{i}}$ Kelvin cinsinden parlaklık sıcaklığı değerini, $\mathrm{T}_{\mathrm{a}}$ ortalama atmosferik sicaklığı, $\tau$ i atmosferik geçirgenlik değerini, $\varepsilon_{\text {i }}$ yüzey yayınırlığını, a ve b algoritma sabitlerini, C ve D yayınırlık ve atmosferik geçirgenlik kullanılarak hesaplanan algoritma parametrelerini ifade etmektedir.

\section{UYGULAMA}

Mono-window algoritması ile elde edilen YYS görüntüleri esasında YIA'nı temsil eden bir parametredir. Gece ve gündüz verileri için üretilen YYS görüntüleri Kelvin biriminde Şekil 2'de gösterilmiştir. Elde edilen YYS görüntüleri, aynı tarihlerde alınan gündüz ve gece MODIS (Moderate Resolution Imaging Spectroradiometer) verileri ile çapraz doğrulama yöntemi ile doğruluk analizine tabi tutulmuştur. Gündüz görüntüsü içine yapılan değerlendirmede, korelasyon katsayısı $\left(\mathrm{R}^{2}\right) \% 90$ ve Karesel Ortalama Hata $(\mathrm{KOH}) 2.05$ Kelvin olarak hesaplanırken gece görüntüsü için $\mathrm{R}^{2} \% 88$ ve $\mathrm{KOH} 2.25$ Kelvin olarak belirlenmiştir.

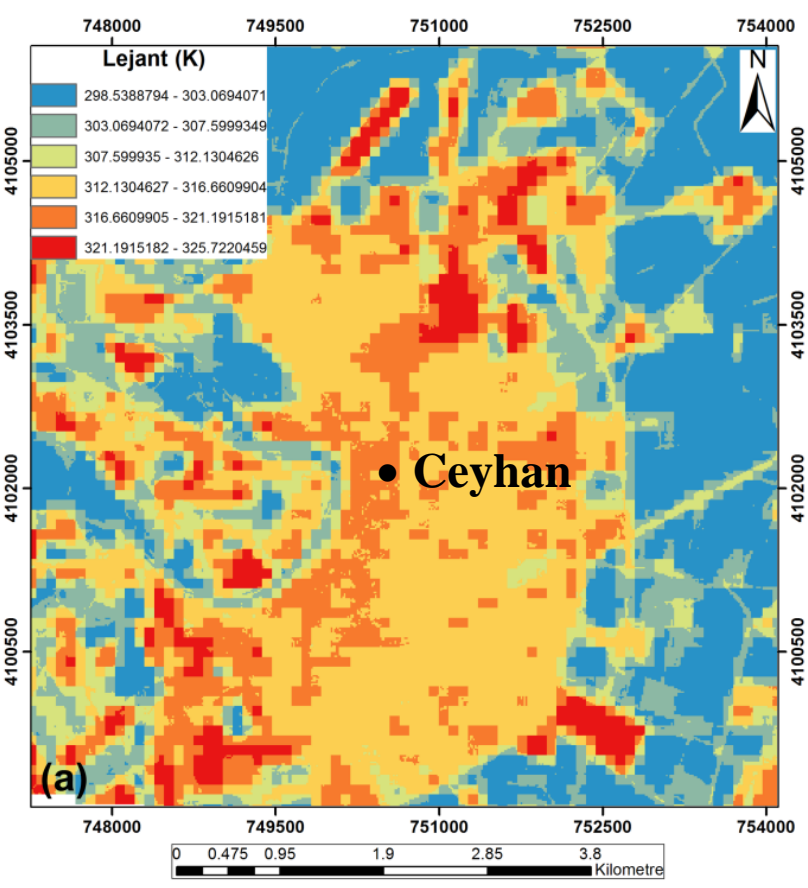

(a) Gündüz

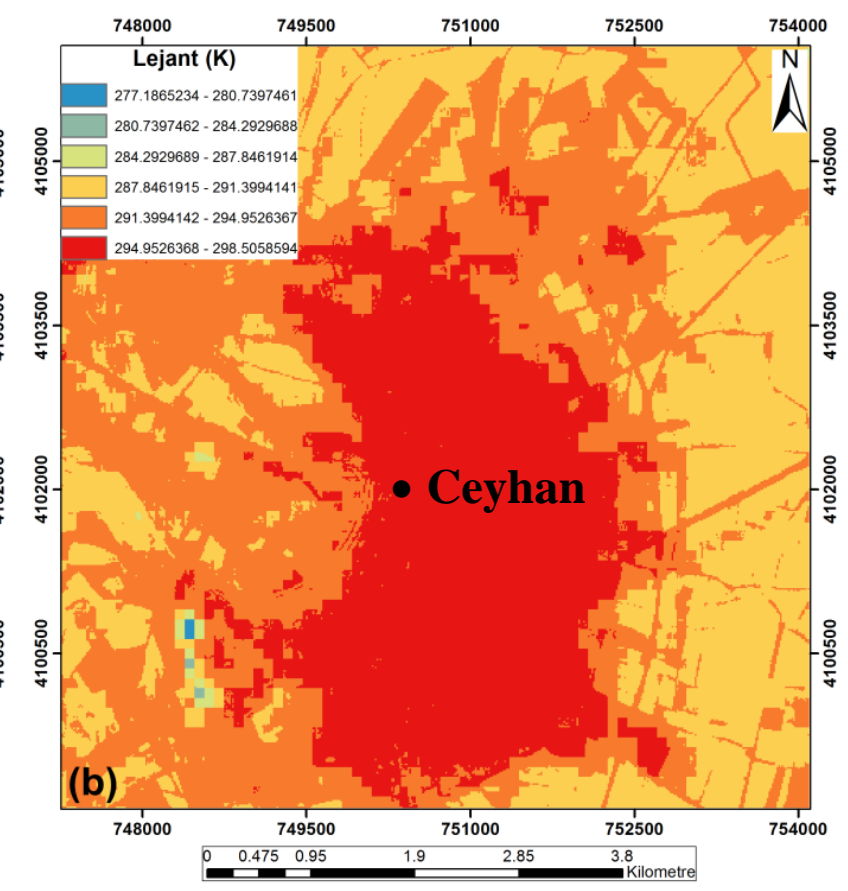

(b) Gece

Şekil 2. ASTER verileri ile üretilen çalışma alanına ait YYS görüntüleri. 
Şekil 2'den anlaşılacağı üzere Ceyhan şehir merkezinin YYS değerlerinin, hem gündüz hem de gece görüntüsünde yüksek değerlerde olduğu gözlemlenmektedir. YYS görüntüleri üzerinden YIA etkisinin analizi için beş farklı AKAÖ seçilmiş ve bu alanlar arazi çalışması yapılarak teyit edilmiştir. Şekil 3'de seçilen beş kategoride; A nadasa bırakılan toprağı, B bitki örtüsü yoğun olan tarlayı, C kentsel alanı, D su yapısını, E bitki örtüsü seyrek tarlayı temsil etmektedir.

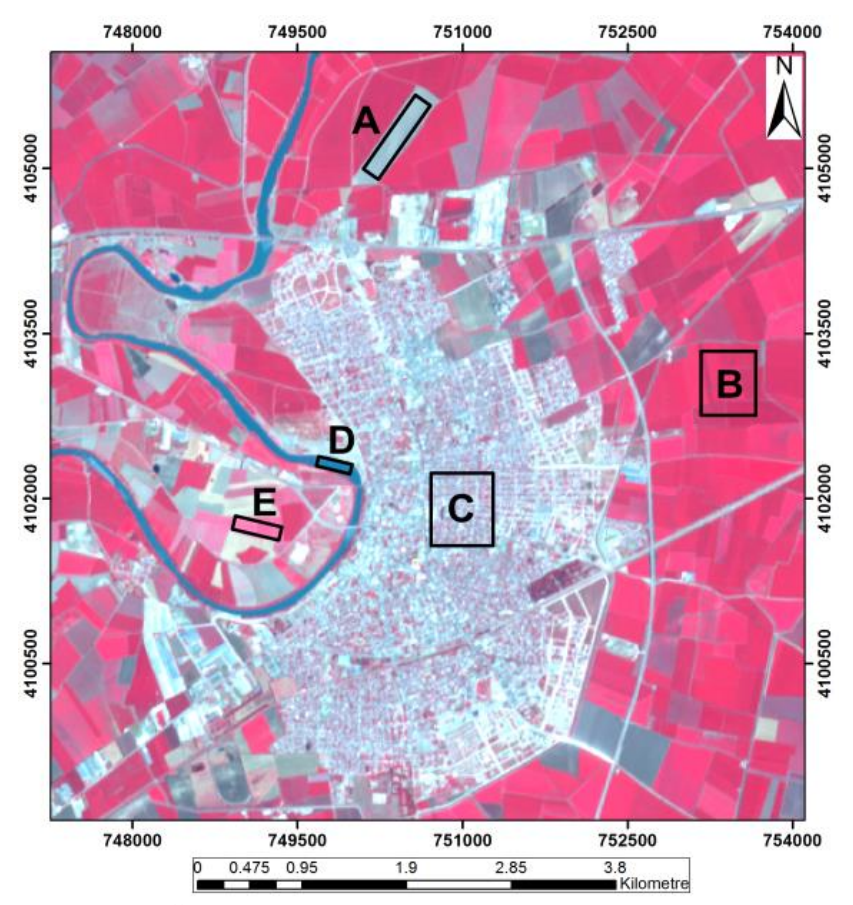

Şekil 3. YIA analizi için seçilen AKAÖ türleri. A: nadasa bırakılan toprağı, B: bitki örtüsü yoğun tarla, C: kentsel alan, D: su yapısı, E: bitki örtüsü yoğun olmayan tarla.

Şekil 2'de belirtilen alanlardaki YYS değerleri çıkarılarak istatistiksel ilişkiler ortaya konulmuştur (Çizelge 3). Çizelge 3'te yer alan ortalama YYS değerleri dikkate alındığında gündüz nadasa bırakılan toprak en yüksek ortalama YYS değerine sahipken, gece kentsel alanın en yüksek ortalama YYS değerine sahip olduğu görülmektedir. En düşük ortalama YYS değerleri ise hem gece hem de gündüz verisinde bitki örtüsü yoğun olan tarlada elde edilmiştir. Çizelge 3'e ek olarak, bu 5 AKAÖ türünden 15 piksellik doğrusal kesitler alınarak Şekil 4'teki grafik elde edilmiştir. Şekil 4'ten de anlaşılacağı üzere Nadasa Bırakılan Toprak gündüz en yüksek YYS değerine sahipken geceleri kentsel alandan daha düşük YYS değerlerine sahip olduğu görülmektedir. Bitki örtüsü yoğun olan tarlanın hem gündüz hem de gece en düşük YYS değerlerine sahip olduğu da belirlenmiştir.

Çizelge 3. Seçilen AKAÖ türleri için çıkarılan YYS istatistikleri.

\begin{tabular}{|c|l|c|c|c|}
\hline YYS Verisi & \multicolumn{1}{|c|}{ AKAÖ } & Maksimum (K) & Minimum (K) & Ortalama (K) \\
\hline \multirow{4}{*}{ GÜNDÜZ } & Nadasa Bırakılan Toprak & 326.5908 & 317.0532 & 324.8282 \\
\cline { 2 - 5 } & Bitki Örtüsü Yoğun Tarla & 301.3471 & 299.3736 & 299.9941 \\
\cline { 2 - 5 } & Kentsel Alan & 317.5828 & 313.9929 & 316.2186 \\
\cline { 2 - 5 } & Su Yapısı & 308.186 & 301.8603 & 305.0645 \\
\cline { 2 - 5 } & Bitki Örtüsü Seyrek Tarla & 314.4394 & 303.5683 & 308.1198 \\
\hline \multirow{4}{*}{ GECE } & Nadasa Bırakılan Toprak & 293.2618 & 292.0318 & 292.6476 \\
\cline { 2 - 5 } & Bitki Örtüsü Yoğun Tarla & 290.2664 & 289.0312 & 289.4815 \\
\cline { 2 - 5 } & Kentsel Alan & 298.0601 & 296.3543 & 297.4643 \\
\cline { 2 - 5 } & Su Yapısı & 295.7771 & 293.9486 & 294.8908 \\
\cline { 2 - 5 } & Bitki Örtüsü Seyrek Tarla & 294.5781 & 291.0934 & 291.9579 \\
\hline
\end{tabular}




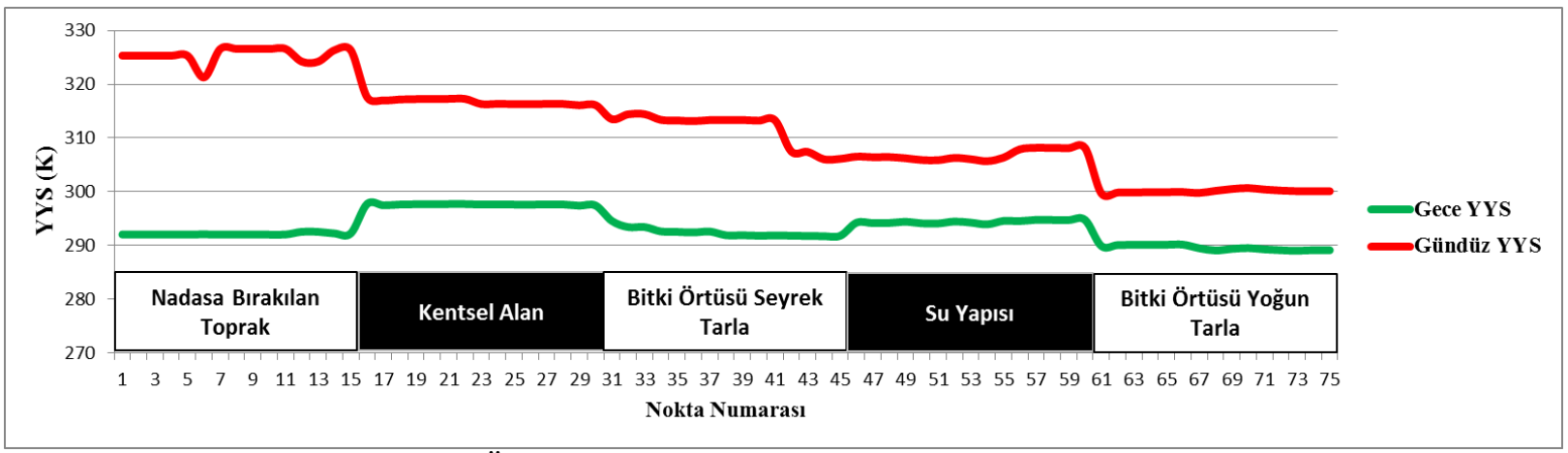

Şekil 4. AKAÖ türleri için YYS görüntüsünden alınan kesitlerin grafiği.

\section{SONUÇLAR}

Bu çalışmada, ASTER algılayıcısına ait veriler kullanılarak mono-window algoritmasıyla gece ve gündüz YYS görüntüleri elde edilmiş ve YYS sonuçları ışığında YIA etkisi analiz edilmiştir. Çalışma alanı olarak Adana ilinin merkez ilçeleri dışındaki en büyük ilçesi olan Ceyhan ilçesi ele alınmıştır. YIA etkisini analiz edebilmek için Ceyhan şehir merkezi çevresinden beş farklı AKAÖ türü ele alınmıştır. Her bir AKAÖ türü için minimum, maksimum ve ortalama YYS değeri çıkarılarak her bir AKAÖ türün için alınan kesitlerden YYS grafiği elde edilmiştir. Yapılan analizler sonucunda, Nadasa bırakılan toprağın gündüz en yüksek YYS değerine sahip olduğu ve gündüz zamanı YIA'na katkı sağladığı görülürken geceleri kentsel alanın en yüksek YYS değerine sahip olduğu belirlenmiştir. Kentsel alanlardaki gündüz YYS değerlerinin, nadasa bırakılan topraktan sonra en yüksek seviyede olması ve buna ek olarak gece en yüksek YYS değerinin yine kentsel alanlarda gözlenmesi, YIA etkisine en fazla katkıda bulanan AKAÖ türünün kentsel alanların olduğunu göstermektedir.

Yersel yöntemlerle de analizleri yapılan KIA etkisinin uzaktan algılama teknolojileri ile analizinde, hem maliyet hem de zaman açısından avantajları olduğu görülmektedir. Ayrıca, uzaktan algılama ile elde edilen sonuçların konumsal ve zamansal analizlere imkân sağlaması, sürdürülebilirlik açısından son derece önem arz etmektedir. Tüm bunlara ek olarak, ASTER verilerinin gece ve gündüz TIR verisi sağlaması, YIA etkisinin analizi için önemli bir veri kaynağı olduğunu göstermektedir.

\section{TEŞEKKÜR}

ASTER verilerini ücretsiz olarak temin etmemizi sağlayan Amerikan Ulusal Uzay Dairesi (NASA) ve Amerikan Jeoloji Birliğine (USGS) teşekkür ederiz.

\section{KAYNAKLAR}

Gillespie, A.R., Rokugawa, S., Matsunaga, T., Cothern, J.S., Hook, S.J., Kahle, A.B., 1998, A temperature and emissivity separation algorithm for advanced space borne thermal emission and reflection radiometer (ASTER) images. IEEE Trans. Geosci. Remote Sens., 36, 1113-1126.

Jimenez-Munoz, J.C., Sobrino, J.A., 2003, A generalized single-channel method for retrieving land surface temperature from remote sensing data. J. Geophys. Res., 108, 4688-4694.

Klok, L., Zwart, S., Verhagen, H., Mauri, E., 2012, The surface heat island of Rotterdam and its relationship with urban surface characteristics. Resources, Conservation and Recycling, 64, 23-29.

Martin, P., Baudouin, Y., Gachon, P., 2015, An alternative method to characterize the surface urban heat island. International journal of biometeorology, 59(7), 849-861.

Peng, S., Piao, S., Ciais, P., Friedlingstein, P., Ottle, C., Bréon, F. M., Nan, H., Zhou, L., Myneni, R. B., 2011, Surface urban heat island across 419 global big cities. Environmental science \& technology, 46(2), 696-703.

Qin, Z., Zhang, M., Amon, K., Pedro, B., 2001, Mono-window algorithm for retrieving land surface temperature from Landsat TM 6 data. Acta Geogr. Sin., 56, 456-466.

Sekertekin, A., Kutoglu, S. H., Kaya, S., 2016, Evaluation of spatio-temporal variability in Land Surface Temperature: A case study of Zonguldak, Turkey. Environmental Monitoring and Assessment, 188(1), 30. 
Sobrino, J. A., Jimenez-Muoz, J. C., Soria, G., Romaguera, M., Guanter, L., Moreno, J., Martinez, P., 2008, Land Surface Emissivity Retrieval From Different VNIR and TIR Sensors. IEEE Transactions on Geoscience and Remote Sensing, 46(2), 316-327.

Sobrino, J.A., Li, Z.L., Stoll, M.P., Becker, F., 1996, Multi-channel and multi-angle algorithms for estimating sea and land surface temperature with ATSR data. Int. J. Remote Sens., 17, 2089-2114.

Şekertekin, A., Kutoğlu, Ş.H., Kaya, S., Marangoz, A.M., 2016, Monitoring The Surface Heat Island (SHI) Effects of Industrial Enterprises. Int. Arch. Photogramm. Remote Sens. Spatial Inf. Sci. XLI-B6, 289-293.

Wang, F., Qin, Z., Song, C., Tu, L., Karnieli, A., \& Zhao, S., 2015, An Improved Mono-Window Algorithm for Land Surface Temperature Retrieval from Landsat 8 Thermal Infrared Sensor Data. Remote Sensing, 7(4), 42684289 . 